\title{
Paper recycling for the making of constructions materials
}

\author{
Tefy Raoelivololona ${ }^{1, *}$, Mamiharijaona Ramaroson ${ }^{2}$, and Chrysostome Raminosoa ${ }^{3}$
}

${ }^{1}$ Ecole Supérieure Polytechnique d'Antsiranana - BP O Antsiranana 201 - Madagascar
${ }^{2}$ Ecole Supérieure Polytechnique d'Antsiranana - BP O Antsiranana 201 - Madagascar
${ }^{3}$ Ecole Supérieure Polytechnique d'Antsiranana - BP O Antsiranana 201 - Madagascar

\begin{abstract}
Madagascar undergoes, like all countries in the world, the effects of climate change. in fact, since the last 5 years, in the coastal regions and the basins, the temperature has raised from 2 to $2.5^{\circ}$ and varies between 34 to $36^{\circ}$ in the shadow during the rainy season and on the high hills, the temperature diminishes from 2 to $2.5^{\circ}$ during the dry period and varies from $4^{\circ}$ to $8^{\circ}$. However, the structure of lodging of $60 \%$ of the people are not adapted to this temperature change. Particularly, in the coastal regions, the walls of the houses are made of sheet iron. The inside of these houses is very hot when the weather is hot and very cold when it is cold. The inhabitants can't afford the houses made in bricks or breeze block and the natural sources of aggregates are in the process of exhaustion. In the other part, we have seen that tons of paper are ready to be burned at the administrative services (public treasury, public financing, universities, ...) and the newspaper publishers. So, it becomes a must to find another way to the construction materials, justifying in that case our research axis. This study aims at the developing of construction material based on recycled paper, binder and aggregate. It deals of picking up or gathering all waste of papers and outdates newspapers and transforming them into brick for building constructions. What's more, papers have prominent thermal insulating properties. Our work is focused on the study of variants on the different manufacturing processes, the choice of binder, the preparation of the specimens with different binders and different dosages, the mechanical compression tests for different binders, the evaluation of thermal conductivity for different binders and the numerical simulation of the thermo mechanical behavior of samples. The result is a lightweight brick with good thermal insulation. Tests have also made it possible to declare that the material has acceptable mechanical properties : the compressive strength is 1.56 [N/mm2], higher than the value prescribed by the standard for lightweight concrete blocks for construction of $1.1[\mathrm{~N} / \mathrm{mm} 2]$, the value of thermal conductivity is $0.114[\mathrm{~W} / \mathrm{mK}]$, ten times less conductive heat than concrete and it can replace glass wool for a double its thickness. The specific weight is $57.5[\mathrm{~kg} / \mathrm{m} 2]$.The practical results were confirmed by finite element simulations.
\end{abstract}

\section{Introduction}

\subsection{Context}

The building sector strongly affects the environment through consumption of natural resources and energy. These consumptions are subsequently accompanied by the emission of waste and pollutants acting on the global, local and internal climate. In this context, it is necessary, inter alia, that buildings should be energy efficient and use materials with low environmental impact.

Moreover, the twelve points under quoted are taken from [20] answering the question "why recycle papers? "

- To produce Sunday newspapers in the United States, 500,000 trees must be cut every week;

- The recycling of all the Sunday Times prints in New York for a day would save 75,000 trees;

- If all our newspapers were recycled, we could save about 250,000,000 trees each year;
- If every American recycles just one tenth of its newspapers, 25,000,000 trees would be spared per year;

- An old 15-year-old tree can produce about 700 bags of grocery paper. A supermarket can use them all in less than an hour! This means, in one year, that a supermarket can use more than 6 million paper bags! Imagine how many supermarkets there are in the world;

- An average American uses seven trees per year for his consumption of paper, wood and other products made from trees;

- The amount of wood and paper we throw each year is enough to heat 50,000,000 homes for 20 years;

- The equivalent of $\$ 1$ billion is wasted every year;

- A household throws an average of 13,000 pieces of paper each year. Most are packaging and spam;

- Each ton of recycled paper can save 17 trees, 3 cubic meters of landfill, 4,000 kilowatts of energy, and 7,000 liters of water;

\footnotetext{
* Corresponding author : vololonatefy@gmail.com
} 
- Paper recycling represents an energy saving of $64 \%$, saving of $58 \%$ of water;

- 17 saved trees are trees that can absorb a total of $250 \mathrm{~kg}$ of carbon dioxide from the air each year.

For our part, the $60 \%$ of the dwellings in the coastal cities are of sheet metal, not adapted to the variations of the climate. And on the other hand, the so-called hard houses are built with cinder blocks whose price is not accessible to $50 \%$ of Malagasy.

\subsection{Literature reviews}

In our bibliographic study, we discover the existence of an approaching material, called "paper binder" or papercrete invented 93 years ago. Different types of papercrete contain $50 \%$ to $60 \%$ of waste paper [13]. The standard mix proportion of papercrete is determined according to the required physical properties such as density, mechanical properties, flame retarded and thermal properties. So the trick is finding the best mix for the application. Design of mix proportion of papercrete was studied by several authors. In some investigations the mix proportions chosen is as follows by [7] : cement - fine aggregate - paper sludge $1: 1: 1$. The mix proportion of fibrous concrete is cement to waste paper is $1: 1,1: 2$ or $1: 3$. The papercrete forming by mixing portland cement : white lime - paper sludge as $1: 0.5: 4$. The amount of water added was enough to produce a workable papercrete. The workability was assessed using drop ball apparatus, where the ball penetration was $10 \pm 1 \mathrm{~mm}$ [9]. Six mix proportion samples were considered in a research study by [10], where waste paper to cement replacement ratio had been kept on increasing scale from 0.5 to 6. [8] studies the compressive strength of papercrete samples of different composites. Theses composites are paper-cement, paperclay, paper-cement-sand, paper-cement-fly ash, papercement-glass, paper-cement-lime with different mix proportions. Its thermal conductivity and water absorption were studied by [14]. The mix proportions of papercrete bricks as cement: rice husk ash: fly ash: paper pulp are 1:2:0:4, 1:3:0:6, 1:1.5:0:4, 1:0:2:4, 1:0:3:6 and 1:0:1.5:4.

[15] study the mechanical properties of papercrete. Waste paper was used as replacement of Portland cement at $5 \%, 10 \%$ and $15 \%$ by weight. It is noted that the density of papercrete was decreased when the replacement ratio of waste paper of papercrete increased. The physical properties of papercrete were reported by [16]. They reported that the density of the papercrete has a trend of decrease as a higher waste paper was included and the compressive strength is variously to be in the range of 140-160 lb/square inch. Papercrete has very good shear strength as a block, the R-value of papercrete is reported to be between 2.0 to 3.0 per inch and papercrete will not burn with an open flame. Density, water absorption, compressive strength and fire resistance of papercrete were studied [18]. Two categories of papercrete were produced using either waste newspaper or waste office paper. For each of the waste newspaper and waste office paper mixtures, the ratios of cement: sand: wastepaper used were 1:1:0.2, $1: 1: 0.4,1: 1: 0.6$ and $1: 1: 0.8$.

Six different proportions of papercrete were used by [17] to study the feasibility of using waste paper in bricks. The mix proportion is designed as cement- rice husk ash- fly ash- sand- paper. The bricks are relatively light weight, good sound absorbent and more flexible but it has high of water absorption than conventional bricks. According to research of [11], there was no formal mix design of papercrete, and effects of water to cement ratio on papercrete were not known. The exact mix proportion of papercrete was not known [12], so trial proportions were used in several studies.

It is concluded that the papercrete is a good thermal and sound insulation. Also the papercrete bricks are suitable for non-load bearing wall only and using the papercrete in the building will be reduced the cost from $20 \%$ to $50 \%$.

All these contexts and the results of the research justify our research which makes a great contribution to the development of innovative building materials with limited environmental and health impacts. It focuses on the development of a construction material based on recycled paper, agglomerate and binder available in Madagascar. It is a matter of recovering all waste paper and antedated newspapers and turning them into brick for building constructions. In addition, the papers possess remarkable properties of thermal and acoustic insulation.

\section{Manufacturing process}

The whole of our manufacturing process is totally artisanal. The basic elements are waste paper, cement, sand and water.

\subsection{Implementation}

The principle consists in mixing the sand, cement and the paper waste into pulp (powder) to dry before gradually pouring water in order to have a material as homogeneous as possible.

The binder-paper assembly is then kneaded. Since the powder is very soft and easy to disintegrate with the addition of the excess water, ten minutes is sufficient to obtain a good homogeneity of the mixture. This greatly reduces energy consumption.

\subsection{Drying}

From the design point of view, knowledge of the drying time is crucial to achieve better performance.

In the following, a cylindrical specimen is made according to the following notation convention: papercement-sand-water 3-1-1-2 represents three quantities of paper, an amount of cement, an amount of sand and a quantity of water (eg $3 \mathrm{~kg}$ of paper pulp, $1 \mathrm{~kg}$ of cement, $1 \mathrm{~kg}$ of sand and 2 liters of water, which is in particular 2 $\mathrm{kg})$. 
Thus, measurements were made for two types of test pieces, 3-1-1-2 and 2-1-1-2. Samples weighed in a regular interval of 12 hours.

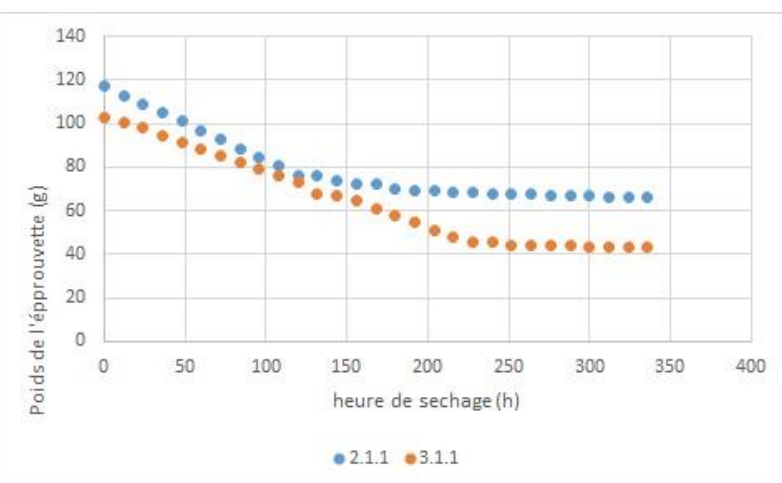

Fig. 1.Weight of the test piece in relation to the drying time

The weight of the 2-1-1 specimen is stable after about 150 hours, ie one week after molding. That of 3-11 asks for cons about 9 days to have a stable weight.

\subsection{Product features}

Density : By way of comparison, we show in the following table the densities of paper + binder, concrete and earth brick.

. Table 1. Comparison of density

\begin{tabular}{cccc}
\hline Product & Paper+binder & agglo & $\begin{array}{c}\text { Clay } \\
\text { brick }\end{array}$ \\
\hline $\begin{array}{l}\text { Density } \\
{\left[\mathrm{kg} / \mathrm{m}^{3}\right]}\end{array}$ & 750 & 2500 & 1600 \\
\hline
\end{tabular}

This table confirms that paper + binder is a lightweight material.

Compressive strength : The test specimen is loaded at a constant speed up to rupture on a machine (INSTRON universal mechanical test stand model 4302 of the High School Polytechnic) for compression testing. The maximum load reached makes it possible to calculate the compressive strength of the material.

For the test, we designed 4 types of test pieces according to the binder and aggregate levels.

Table 2. Different compositions of the test piece

\begin{tabular}{ccccc}
\hline Tube test & paper & sand & cement & water \\
\hline e1 & 3 & 1,5 & 0,5 & 4 \\
e2 & 3 & 1 & 1 & 4 \\
e3 & 2 & 1 & 1 & 2,5 \\
e4 & 1 & 2 & 1 & 2 \\
\hline
\end{tabular}

The result curve is shown in the following figure 2 :

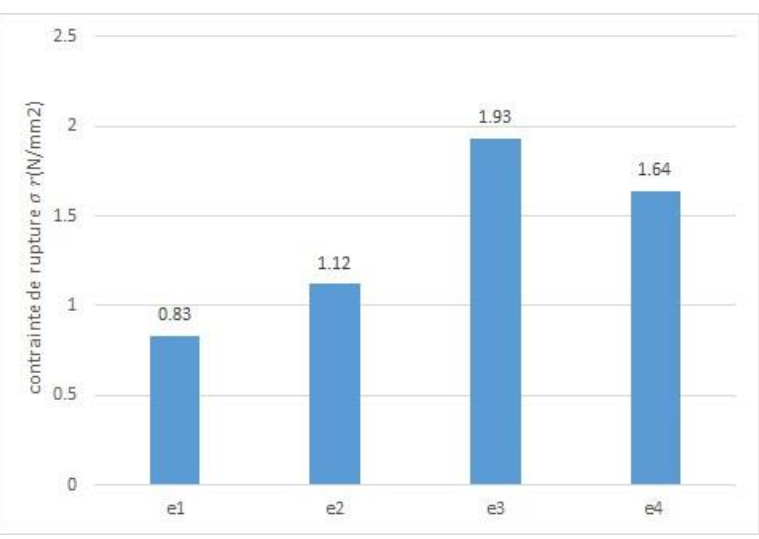

Fig.2. Breaking stress by type of test piece

The European standard DIN EN 771-3 suggests that a compressive strength of $1.1 \mathrm{~N} / \mathrm{mm} 2$ is acceptable for lightweight concrete blocks for construction. Thus, the test piece e3 $(2-1-1-2,5)$ exhibits a maximum rupture stress allowing it to be chosen as an optimal formulation.

Other types of test specimen were made with aggregate lime, plaster and basalt powder. In all cases, the stress is maximum in the proportion 2-1-1-2,5.

Thermal Conductivity : To heat, cool, ventilate you need energy and to reduce the consumption of this energy, you use a building material with low thermal conductivity. Thus, the optimization of this parameter is unavoidable.

The following table shows the comparative values of the dry thermal conductivity coefficient of some materials with respect to the two types of test specimen.

Table 3. Comparison of thermal conductivity

\begin{tabular}{|c|c|}
\hline Matériau & $\begin{array}{l}\mathrm{k}(\mathrm{W} / \mathrm{mK}) \\
\mathrm{k}: \text { thermal } \\
\text { conductivity }\end{array}$ \\
\hline e $3-1-1$ & 0,106 \\
\hline e $2-1-1$ & 0,114 \\
\hline extruded polystyrene & 0,037 \\
\hline glass wool & 0,038 \\
\hline agglo & 1,25 \\
\hline
\end{tabular}

These values indicate that our material has exceptional thermal conductivity for a building material. It is ten times less heat conductive than concrete. It can replace glass wool for a double its thickness, yet with its mechanical property, it can benefit from the bearing function for a building for example.

Fire resistance : The test method is truly artisanal by burning the specimen on a large fire. But the test piece did not catch fire after 2 hours as shown in the figure below (figure on the right) 


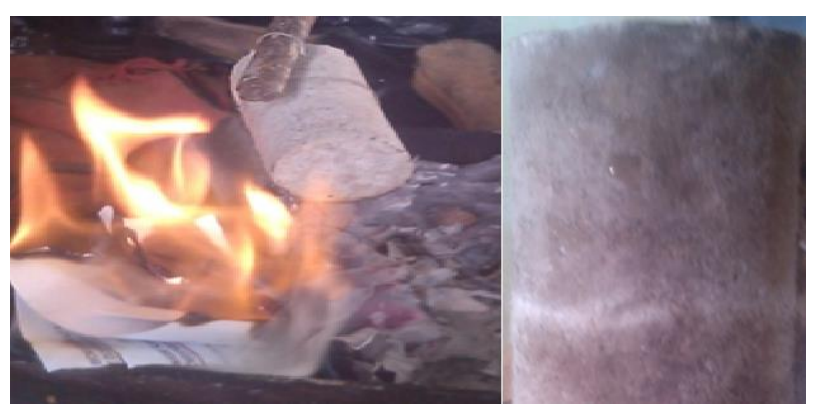

Fig. 3. Artisanal process for fire resistance

So, our material can be used in the part like the chimney.

Surface mass : In the field of civil engineering, the mass per unit area of a building element is required to estimate whether the element can be used in higher floors. For a vertical punch brick model, it takes 12.5 units for a surface area of $1 \mathrm{~m}^{2}$ which is $57.5 \mathrm{~kg} / \mathrm{m}^{2}$.

\section{Numerical simulation}

The simulations relate to compression and heat transfer. We used the COMSOL Multiphysics software.

Simulation on compression : The following figure shows the distribution of the stresses. It can be seen that the middle parts of the specimen dilate because the stress is maximum. The maximum value is about $1.85 \mathrm{~N} / \mathrm{mm}^{2}$ which matches the value found during the machine tests.

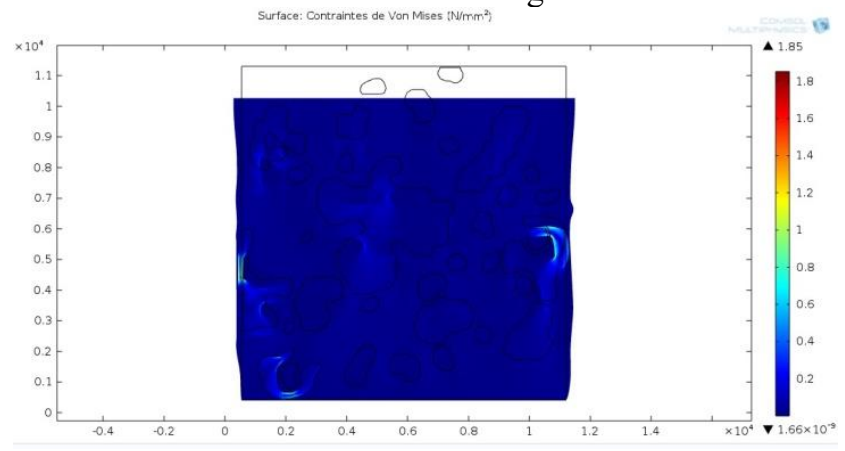

Fig. 4. Result of the compression simulation

Simulation of the thermal transfer : The result of the simulation is given in figure 5 given below.

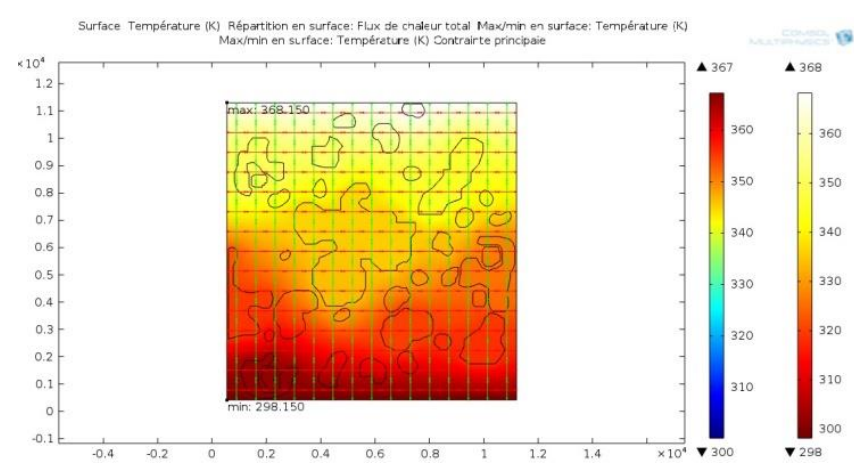

Fig. 5. Result of thermal transfer simulation
We observe that the temperature is maximum on the outer surface (bottom) and minimal in the inner wall (upwards).

\section{Conclusion}

Paper brick is a promising building material because it has a combination of outstanding mechanical and thermal performance. Undoubtedly, this innovative material has great potential to revolutionize building materials. A great advantage also lies in the ease of manufacture.

This study was for us the opportunity to confront an idea with a technical reality, and the passage from the creation of matter into a building material. Moreover, this research has given us a certain rigor on the operating mode and the learning of the characterization of several aspects of a material.

The environmental aspect of research is a largely stimulating factor. Indeed, in tackling the issue of paper, we were far from imagining the amount of untapped resources and the monumental waste that this represents on the planet. Yet the paper problem is anecdotal from the environmental point of view, and forces us to consider in a wider awareness the importance of the treatment of our waste and our modern modes of production / consumption. These environmental issues must be taken into account at the design stage.

The brick of paper is a very interesting material as well in summer as in winter. Indeed, it allows to keep the heat inside a room, but also to make a dam to the outside heat. It is an insulating material with high thermal resistance and is therefore attractive for the construction of low-cost buildings.

Although we have specified the basic characteristics to identify our material, work is still to be expected for more confirmations. Specific formulations should be defined for each part of the building. One could then have a formulation for the roof, another for the wall, for the construction briquette or even for solid concrete.

It is urgent to use this product to double the sheet metal walls thus reducing the heat inside the houses. At first, we plan to build a pilot house with our building materials.

We can also add plant debris to have composite materials whose different proportions are to be studied.

\section{Keywords}

Construction material, paper recycling, thermal insulation, paper brick, lightweight material, high thermal resistance, construction briquette, composite materials.

\section{References}

1. Norme européen de spécification des éléments de maçonnerie. NF EN 771-1. 2011

2. Ali, A., Hashmi, H.N. Baig, N., Treatment of the paper mill effluent, Revue 2013 
3. Ballon Camille. Enjeux et réusage des matières disponibles. Mémoire de Master 2, Ecole Nationale Supérieure d'Architecture de Paris Malaquais, 2014

4. Étude multi-échelles des couplages entre les propriétés hygroélastiques des papiers et leur microstructure. Thèse de doctorat. Cyril MARULIER. 2013

5. Kmecová Veronika et al. Effect of Basalt Powder on Workability and Initial Strength of Cement Mortar. Journal of Civil Engineering and Architecture Research, 2014

6. Dr. Fixit Pidiproof LW . Liquid integraL Water Proofing Compound for Concrete and Plaster. Manuel d'utilisation, 2010

7. G. V. S. Siva Prasad, P. Padmanabha Reddy, M. Swathi, P. D. V. Kiran Kumar, T. Praveenraja and M. Naveen, (2015), Study and behavior of some properties of papercrete brick with modular brick, International journal of Engineering Research, Vol.3, Issue 3.

8. J. Santamaria, B. Fuller and A. Fafitis, (2007), Structural properties of a new material made of waste paper, WIT Transaction on Modelling and Simulation, Vol.46.

9. Bashar S. Mohammed, (2009), Papercrete as infill materials for composite wall system, European Journal of Scientific Research, Vol.34, No.4.

10. Saurabh Chandarana, Jayesh Charthal and Yogesh Chandarana, (2015), Experimental study and evaluation of optimum mix proportion of papercrete blocks, International Journal of Modern Trends in Engineering and Research (IJMTER), Vol.2, Issue 2.

11. Joo-Hong Chung, Byoung-Hoon Kim, Hyun-Ki Choi and Chang-Sik Choi, (2000), Development of papercrete due to paper mixing ration, International Conference on Sustainable Building Asia, SB10 Seoul.

12. T. Subramani and V. Angappan, (2015), Experimental investigation of papercrete concrete, IJAIEM, Vol. 4, Issue 5 .

13. K. Anandaraju, B. Jose Ravindra Raj and R. Vijaya Sarathy, (2015), Experimental investigation of papercrete brick, IJMCE, Vol. 2, Issue 2.

14. AGilan. V., (2015), Energy saving lightweight bricks using waste newspaper, Quest for advancement in Civil Engineering.

15. H. Yun, H. Jung and C. Choi, (2007), Mechanical properties of papercrete containing waste paper, $18^{\text {th }}$ international conference on composite materials, Architectural Institute of Korea, Korea

16. Shivangni Khandelwal, Kishan Lal Prajapat and Mukul Kumar, (2015), Review on papercrete, IJCRD, Vol. 4. Issue 6.

17. Ms. S. Suganya, (2012), Lightweight bricks- made up of waste papers, International Journal of computer and organization trends, Vol. 2, Issue 2, No. 2.
18. Isaac I. Akinwumi, Olasunkanmi M. Olatunbosun, Oluwarotimi M. Olofinnade and Paul O. Awoyera, (2014), Structural evaluation of lightweight concrete produced using waste newspaper and office paper, Civil and Engineering Research, Vol. 6, No. 7.

19. Md. Safiuddin, (2008), PhD Thesis, Development of Self-consolidating High Performance Concrete Incorporating Rice Husk Ash, Waterloo, Ontario, Canada.

20. http://entreprise-environnement.org/recyclage-dupapier/ 